\title{
Comparison between the effects of the benzodiazepine receptor ligands methyl beta-carboline-3-carboxylate and diazepam in two learning situations in mice
}

\author{
GEORGES CHAPOUTHIER, MARIE-JOSEE RAFFALLI-SEBILLE, and PATRICE VENAULT \\ Département de Psychophysiologie, Laboratoire de Physiologie Nerveuse, CNRS \\ Gif-sur-Yvette, France \\ and Laboratoire Génétique, Neurogénétique et Comportement, CNRS, Université Paris V \\ Paris, France \\ JACQUES SIMIAND \\ Sanofi Recherche, Toulouse, France \\ and \\ ROBERT H. DODD \\ Institut de Chimie des Substances Naturelles, CNRS, Gif-sur-Yvette, France
}

\begin{abstract}
Benzodiazepines are known to induce profound amnesia in man. In this report, we show, in mice, that whereas benzodiazepine diazepam indeed impairs performance, methyl beta-carboline3 -carboxylate ( $\beta$-CCM), an inverse agonist of the benzodiazepine receptor, on the contrary enhances performance. The two learning situations used were one-trial passive avoidance and multiple-trial light-dark discrimination in a T-maze. Since these effects are blocked by Ro 151788 , a specific antagonist of the benzodiazepine receptor, they are likely to be mediated by the benzodiazepine receptor. They seem to involve action on learning rather than on memory.
\end{abstract}

Benzodiazepines are widely used anxiolytics and anticonvulsants. Their potent sedative properties are routinely used in presurgical anesthesia. In the 1960s, anesthetists reported that benzodiazepines induced a strong anterograde amnesia in patients (Lister, 1985). Specific substances that can block the effects of benzodiazepines have recently been described (Braestrup, Nielsen, \& Olsen, 1980; Hunkeler et al., 1981). Interestingly, aside from classical antagonists, some of these substances have intrinsic pharmacological properties that are opposite to those of benzodiazepines; they have been called inverse agonists (Braestrup, Schmiechen, Neef, Nielsen, \& Petersen, 1982; Polc, Bonetti, Schaffner, \& Haefely, 1982). Although benzodiazepines usually have an anticonvulsive activity, inverse agonists have been shown to be proconvulsant or convulsant (Oakley \& Jones, 1982; Prado de Carvalho et al., 1984). Inverse agonists are also anxiogenic (Corda, Blaker, Mendelson, Guidotti, \& Costa, 1983; Dorow, Horowski, Paschelke, Amin, \& Braestrup, 1983; File, Lister, \& Nutt, 1982; Ninan et al., 1982; Prado de Carvalho, Grecksch, Chapouthier, \& Rossier,

\footnotetext{
We would like to thank Catherine Marchaland for her help with the statistics. The preparation of this paper was supported by the ATPPharmacologie des Neuromédiateurs (CNRS), and ASP-PIRMED neurodrogues (CNRS), by INSERM (PRC 121 022) and by DRET 84/039. All correspondence should be addressed to $\mathrm{G}$. Chapouthier, Laboratoire Génétique, Neurogénétique et Comportement, UFR Biomédicale, 45 Rue des Saints-Pères, 75006, Paris, France.
}

1983), whereas benzodiazepines are anxiolytic. Finally, although benzodiazepines produce amnesia, several recent reports, including ours, show that inverse agonists enhance performance both in animals (Chapouthier, Venault, Prado de Carvalho, Simiand, \& Rossier, 1984; Venault, Chapouthier, et al., 1986) and in humans (Duka, Stephens, Krause, \& Dorow, 1987).

Our purpose in the present paper is to compare the effects of one of these inverse agonists, methyl betacarboline-3-carboxylate $(\beta-\mathrm{CCM})$ with those of benzodiazepine diazepam in mice. Two different situations are used: a one-trial situation (passive avoidance) and a multiple-trial situation (light-dark discrimination in a T-maze).

\section{METHOD}

\section{Animals}

The subjects were Swiss male mice (25-30 g) (CD1 Charles Rivers, France, for the passive avoidance task, and Iffa-Credo, France, for the choice situation). They were kept 10 per cage in our animal quarters at $25^{\circ} \mathrm{C}$, on a $12: 12$-h light:dark cycle. All experiments were undertaken between 10:00 am and 4:00 pm.

\section{Drugs}

$\beta$-CCM, synthesized by one of us (R.H.D.), was dissolved in $0.1-\mathrm{N} \mathrm{HCl}$ and diluted to volume with saline. Diazepam, provided by Hoffmann-La Roche, Paris ( $1 \mathrm{mg} / \mathrm{ml}$ solution), was diluted to volume in saline. Ro $15-1788$, kindly provided by W. Haefely (Hoffmann-La Roche, Basel, Switzerland), was suspended in sa- 
line with a drop of Tween 80 . Drugs were administered subcutaneously (s.c.) or intraperitoneally (i.p.) in a volume of $0.05 \mathrm{ml} / 10 \mathrm{~g}$ (body weight).

\section{Passive Avoidance Model}

The mice were trained in a single-trial procedure. The animals were placed in an illuminated box connected to a dark box. Entrance into the dark box usually occurred within $30 \mathrm{sec}$ and was punished by an electric footshock. On the next day (test session), the same mice were placed again in the illuminated box. Mice staying in the illuminated box for more than $60 \mathrm{sec}$ were considered as remembering the task. Retention could thus be quantified by the percentage of animals avoiding the dark compartment.

The mice were injected with saline (s.c. or i.p.), $\beta$-CCM $(0.1$, $0.2,0.3$, and $0.4 \mathrm{mg} / \mathrm{kg} \mathrm{s.c.}$ ), or diazepam (1, 2, or $4 \mathrm{mg} / \mathrm{kg}$ i.p.). Either $15 \mathrm{~min}$ (saline, $\beta$-CCM) or $30 \mathrm{~min}$ (saline, diazepam) later, they were placed in an illuminated box $(10 \times 10 \times 12 \mathrm{~cm})$ connected to a large dark box $(23 \times 16 \times 12 \mathrm{~cm})$ with an electrified metallic grid floor. Upon stepping into the dark box, the mouse received a footshock. In order to obtain clear-cut effects, we decided to use two different situations: In experiments with $\beta$-CCM, where facilitation of retention was investigated, a low shock $(0.1 \mathrm{~mA}$ for $2 \mathrm{sec}$, unscrambled dc current) was delivered. In experiments with diazepam where impairment of retention was investigated, a high shock (0.6 mA for $2 \mathrm{sec}$, unscrambled dc current) was delivered. In the $\beta$-CCM-treated groups, there were 20 subjects per group, except in the case of the control group $(0.2 \mathrm{mg} / \mathrm{kg})$, where this number was 40 . The diazepam-treated groups and their control group each contained 12 subjects.

To investigate whether the effects of $\beta$-CCM and diazepam are mediated by the benzodiazepine receptor, an attempt was made to block them, in a second experiment, with the specific benzodiazepine antagonist Ro 15-1788 (Braestrup et al., 1980; Hunkeler et al., 1981).

Groups of mice ( $n=40$ for the low-shock groups; $n=19$ for the high-shock groups) were injected before the first session with saline, $\beta$-CCM $(0.3 \mathrm{mg} / \mathrm{kg} \mathrm{s.c.)}$, diazepam ( $4 \mathrm{mg} / \mathrm{kg}$ i.p. $)$, or Ro 15 1788 (15 mg/kg i.p.), or with a combination of $\beta$-CCM + Ro 151788 or of diazepam + Ro 15-1788. Ro 15-1788 was administered $15 \mathrm{~min}$ before the first session; the remaining injections were performed as described earlier.

\section{Light-Dark Choice Situation}

The training apparatus was a $4.5 \times 4.5 \mathrm{~cm}$ section $\mathrm{T}$-maze, consisting of a $15-\mathrm{cm}$-long departure alley and two $10-\mathrm{cm}$-long choice alleys. The walls and ceiling of the maze were made of transparent plastic. The floor consisted of a metallic grid that could be electrified. The three alleys could be electrified separately, and the connecting square was electrified together with the departure alley. The two choice alleys could be lit with a $25-\mathrm{W}$ electric bulb situated above the ceiling.

Training consisted of six successive daily sessions of 10 trials each. Because our population of mice had a slight tendency to prefer the lit alley, the animals were trained to choose the dark alley. For a given trial, a mouse was placed at the entrance of the departure alley. It had $30 \mathrm{sec}$ to choose between the lit or the dark alley. Past this delay, it was forced to choose by application of a 50- $\mu \mathrm{A} 2-\mathrm{sec}$ electric footshock. If it chose the lit alley, it received additional $50-\mu$ A 2 -sec electric footshocks separated by 2 -sec intervals until it chose the dark alley. If it chose the dark alley, it could escape the maze, and it was, after $30 \mathrm{sec}$, placed at the entrance for another trial. An error was counted only when an animal entered the lit alley. Thus, only errors in discrimination were counted as errors. The speed of response was not investigated, since this discrimination procedure appeared to be a better measure. Light or darkness was distributed to the left or right arm of the maze according to a Gellerman's sequence.
In a first experiment, $10 \mathrm{~min}$ before the first three sessions, the animals were administered $\beta-\mathrm{CCM}(0.3 \mathrm{mg} / \mathrm{kg}$, the most active dose in the passive avoidance model $)$, diazepam $(2.5 \mathrm{mg} / \mathrm{kg})$, or saline. In a second experiment, again $10 \mathrm{~min}$ before each of the first three sessions, the animals received two simultaneous injections of $\beta$ CCM and Ro 15-1788, $\beta$-CCM and the Ro 15-1788 vehicle, Ro 151788 and the $\beta$-CCM vehicle, both vehicles, or one injection of saline. For the first experiment, the subjects numbered 20 in the control group and 16 in the other groups. In the second experiment, each group consisted of 16 subjects.

\section{Statistical Analysis}

The chi-square with Yates's correction allowed us to compare the percentages of the passive avoidance model. One-way analysis of variance was used in the light-dark choice situation.

\section{RESULTS}

\section{Passive Avoidance Model}

As is described in the Method section above, two different groups of mice were used. When facilitation of retention was to be investigated, a low-intensity shock was delivered; when impairment of retention was to be investigated, a high-intensity shock was used. In the low-shock group (Figure 1A), controls showed a poor level of retention,
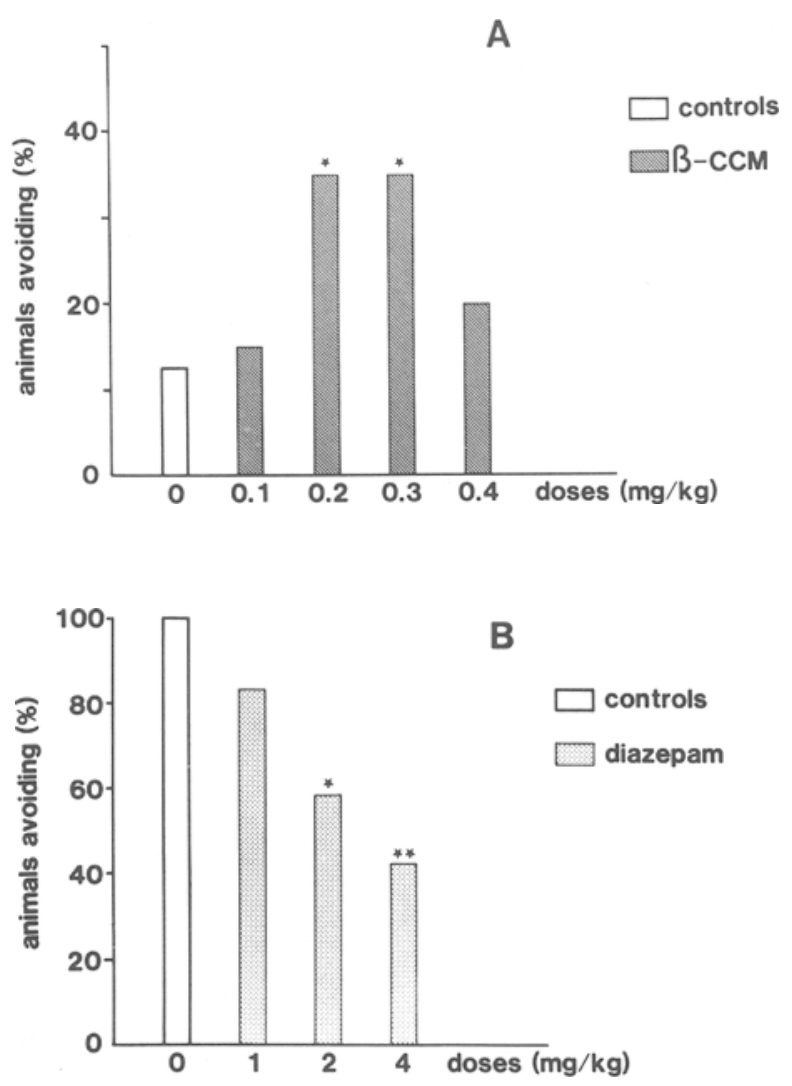

Figure 1. Effects of $\beta$-CCM and diazepam on retention $24 \mathrm{~h}$ after a passive avoidance task in mice. The percentages of animals avoiding the dark box are presented in the figure. (A) $n=20$ per group, except for controls and $\beta-C C M 0.2 \mathrm{mg} / \mathrm{kg}$, where $n=40$. (B) $n=12$ per group. ${ }^{*} p<.05$; ${ }^{* *} p<.01$, between treated and controls. 
Table 1

Reversal of the effects of $\beta-C C M$ by Ro $15-1788$ in Passive Avoidance in Mice

\begin{tabular}{lc}
\hline \multicolumn{1}{c}{ Drug Injected } & \% Animals Avoiding \\
\hline Saline & 17.5 \\
Ro $15-1788$ & 20 \\
$\beta-C C M$ & $40^{*}$ \\
$\beta-C C M+$ Ro $15-1788$ & $15 \dagger$ \\
\hline${ }^{*} \chi^{2}=3.84, p<.05$, as compared with saline-treated $\dagger \chi^{2}=9.60$, \\
$p<.001$, as compared with subjects treated with $\beta-C C M$ alone.
\end{tabular}

and, during the test session, only a small percentage (12\%) of subjects avoided the dark box. In this low-shock group, when $\beta$-CCM $(0.2$ and $0.3 \mathrm{mg} / \mathrm{kg})$ was administered before the training session, a much higher percentage (35\%) of the animals now avoided the dark box during the test session (as compared with controls, for $\beta$-CCM $0.2 \mathrm{mg} / \mathrm{kg}, \chi^{2}=5.59, p<.05$; for $\beta$-CCM $0.3 \mathrm{mg} / \mathrm{kg}$, $\left.\chi^{2}=4.22, p<.05\right)$. Lower $(0.1-\mathrm{mg} / \mathrm{kg})$ doses of $\beta$-CCM were less effective. The performance-enhancing effect of $\beta$-CCM in this task is in direct opposition to the amnesic effect of diazepam (1-4 mg/kg). Thus, in the high-shock group, the percentage of mice avoiding the dark box during the test session was reduced from $100 \%$ (controls) to nearly $40 \%$ (diazepam-treated) (Figure 1B) as compared with controls (for diazepam $2 \mathrm{mg} / \mathrm{kg}, \chi^{2}=6.32$, $p<.05$; for diazepam $4 \mathrm{mg} / \mathrm{kg}, \chi^{2}=9.88, p<.01$ ).

Control measurements showed that, during the training session, latency in entering the dark box did not differ
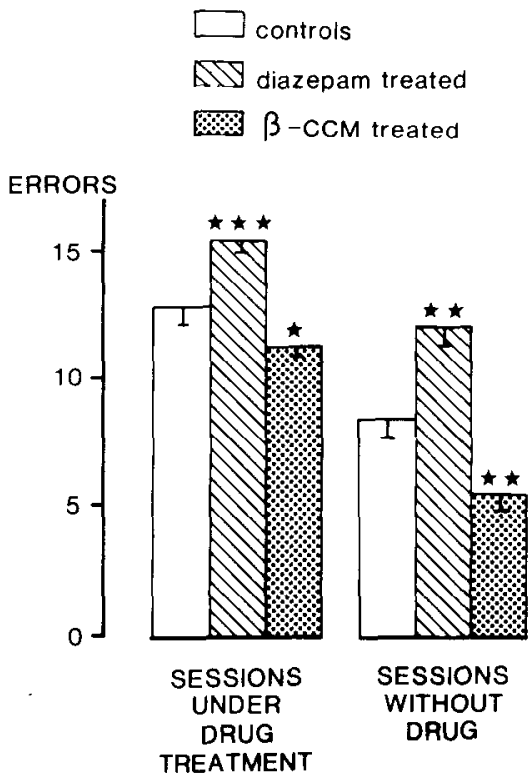

Figure 2. Effects of diazepam and $\beta-C C M$ on performance in maze learning. The bars represent the number of errors $(M \pm S E)$ of the different groups of animals during the $\mathbf{3 0}$ trials of the first three sessions under drug treatment or of the last three sessions without drug. Open bars, controls $(n=20)$; hatched bars, diazepam-treated $(2.5 \mathrm{mg} / \mathrm{kg}, n=16)$; dotted bars, $\beta$-CCM-treated $(0.3 \mathrm{mg} / \mathrm{kg}, n=$ 16). ${ }^{*} p<.005 ;{ }^{* *} p<.01 ;{ }^{* * *} p<.001$, as compared with respective controls. significantly under the influence of the different drugs ( $M \pm S E$, in seconds): $\beta$-CCM controls, $9.8 \pm 1.0$; $\beta-\mathrm{CCM} 0.2 \mathrm{mg} / \mathrm{kg}, 8.8 \pm 1.1 ; \beta-\mathrm{CCM} 0.3 \mathrm{mg} / \mathrm{kg}, 10.8$ \pm 1.1 ; diazepam controls, $10.5 \pm 0.9$, diazepam $2 \mathrm{mg} / \mathrm{kg}, 15.5 \pm 2.6$; diazepam $4 \mathrm{mg} / \mathrm{kg}, 16.3 \pm 4.2$. Thus, differences in performance during the test session cannot be attributed to differences in latencies during the training session.

In a control experiment, shock was not delivered in the dark box. Instead, after having stepped into the dark box during the first session, the mice were returned to their home cages for $5 \mathrm{~min}$; they were then shocked in a different lit box, thus dissociating the dark box from punishment. Twenty-four hours later, during the test session, no difference was observed between saline and treated subjects. The percentages of animals ( $n=15$ per group) avoiding the dark box were: saline, $8 \% ; \beta$-CCM $0.2 \mathrm{mg} / \mathrm{kg}, 0 \% ; \beta-\mathrm{CCM} 0.3 \mathrm{mg} / \mathrm{kg}, 17 \%$. This control experiment rules out a nonspecific effect of $\beta$-CCM on avoidance of the dark box.

The results of the experiments with Ro 15-1788 (Table 1) showed that this compound had no effect when administered alone. However, the effects of $\beta$-CCM were completely antagonized by coadministration of Ro 151788. This could indicate that the effects of $\beta-C C M$ are mediated by the benzodiazepine receptor.

\section{Light-Dark Choice Situation}

In the first experiment, the animals received saline, diazepam, or $\beta$-CCM. Analysis of variance provides evidence that all groups improved their performance in successive training sessions, as is shown by the difference in errors between the first three sessions and the last three [controls, $F(1,38)=25.60, p<.001$; diazepam treated, $F(1,30)=9.78, p<.01 ; \beta-\mathrm{CCM}$ treated, $F(1,30)=$ $14.75, p<.001]$. Global analysis of variance shows a significant effect of drugs for the first 3 days $[F(2,49)=$ $20.11, p<.001]$, as well as for the last 3 without injection $[F(2,49)=20.11, p<.001]$. Detailed analysis (Figure 2) reveals that performance is impaired by the administration of diazepam (increase in the number of errors), both during the sessions under drug treatment [diazepam vs. controls, $F(1,34)=14.75, p<.001]$ and during the sessions without drug $[F(1,34)=10.50, p<$ $.01]$. The opposite effect-that is, an improvement in performance (reduction of the number of errors) - was obtained with $\beta$-CCM, both during the sessions under drug treatment $[\beta$-CCM vs. controls, $F(1,34)=7.13, p<.05]$ and during the sessions without drug $[F(1,34)=11.0$, $p<.01]$.

In the second experiment, the animals received simultaneous administration of $\beta$-CCM + Ro 15-1788, $\beta$-CCM + vehicle of Ro 15-1788, Ro 15-1788 + vehicle of $\beta$-CCM, both vehicles, or saline. As before, all groups improved their performance with training, as is shown by the difference in errors between the first and last three sessions [controls, $F(1,30)=56.96, p<.001$; vehicles, $F(1,30)=34.08, p<.001 ; \beta-C C M$ alone, $F(1,30)=$ 
Table 2

Reversal of the Effects of $\beta$-CCM by Ro 15-1788 in the Light-Dark Choice Situation

\begin{tabular}{|c|c|c|c|c|}
\hline \multirow[b]{2}{*}{ Drug Injected } & \multicolumn{2}{|c|}{$\begin{array}{l}\text { Errors During the } \\
3 \text { First Days ( } 30 \text { Trials) } \\
\text { under Drug Treatment }\end{array}$} & \multicolumn{2}{|c|}{$\begin{array}{c}\text { Errors During the } \\
3 \text { Last Days ( } 30 \text { Trials) } \\
\text { without Dnig }\end{array}$} \\
\hline & $M$ & $S E$ & $M$ & $S E$ \\
\hline Saline & 13.5 & 0.6 & 6.8 & 0.6 \\
\hline Ro 15-1788 & 10.9 & $0.5^{*}$ & 4.25 & $0.7 \ddagger$ \\
\hline$\beta-\mathrm{CCM}$ & 10.2 & $0.7 t$ & 3.9 & 0.68 \\
\hline$\beta-\mathrm{CCM}+$ Ro $15-1788$ & 12.9 & 0.6 & 6.7 & $0.6^{\circ}$ \\
\hline Both vehicles & 13.3 & 0.6 & 7.4 & 0.9 \\
\hline
\end{tabular}

$p<.001 . \quad \$ F=11.44, p<.001$.

$53.33, p<.001$; Ro $15-1788$ alone, $F(1,30)=62.42$, $p<.001 ; \beta-C C M+$ Ro $15-1788, F(1,30)=54.95$, $p<.001]$ (Table 2). Global analysis of variance shows a significant effect of the drugs during the first 3 days $[F(4,75)=6.53, p<.001]$, as well as during the last 3 days $[F(4,75)=5.70, p<.001]$. Detailed analysis reveals that vehicle-treated groups did not differ from controls. Ro 15-1788 alone, as well as $\beta$-CCM alone, improved performance both during the sessions under drug treatment $[\beta-\mathrm{CCM}$ vs. controls $F(1,34)=13.54$, $p<.001$; Ro $15-1788$ vs. controls, $F(1,30)=10.04$, $p<.001]$ and during the sessions without drugs $[\beta-C C M$ vs. controls, $F(1,34)=11.44, p<.001$; Ro $15-1788$ vs. controls, $F(1,30)=7.75, p<.01]$. There was no difference, however, between the $\beta$-CCM + Ro 15-1788 group and the controls, during either the first three or the last three (without drug) sessions. Thus, Ro 15-1788 suppressed the effects of $\beta$-CCM administered alone.

\section{DISCUSSION}

Our results provide evidence for the enhancing effect of $\beta$-CCM on learning in both a one-trial passive avoidance task and a multiple-trial learning task. The action of diazepam was found to be directly opposite. If we consider that $\beta$-CCM acts at some stage of learning or memory processing, the question remains as to which stages of learning or memory are affected by the drug. If memory can be defined as the retention of information, this information needs to be acquired (learning) and then recalled (retrieval). In another behavioral task, habituation to a new environment (Venault, Chapouthier, et al., 1986 ), we showed that $\beta$-CCM had no effect when administered before the retention test. We could thus rule out an action on retrieval and suggest that $\beta$-CCM was acting on learning. This is in agreement with most results obtained with benzodiazepines in human subjects. But more direct proof was needed in animals. Using a lightdark choice situation, we verified that the effects of $\beta$-CCM observed using passive avoidance during the test session were already observable under drug treatment. As for passive avoidance, $\beta$-CCM improvement of performance was evident when the animals were no longer under treatment (the last three sessions). But this improvement could already be seen during the administration of $\beta$-CCM (the first three sessions). This observation could not be made in the one-trial learning procedure. Though more work should still be done in this area, our data seem to rule out a state-dependency interpretation of the effects of $\beta$-CCM and diazepam. A state-dependency hypothesis would require that effects observed under drug treatment would not persist when the drug was no longer administered. Another objection could involve the electric footshock. It is well known that many treatments (e.g., ACTH, MSH, and even ECS) impair memory for training with intense footshocks and improve memory for training with weak footshocks. In the passive avoidance task, the fact that two levels of footshock were used could offer an alternative explanation for the difference observed between $\beta$-CCM and diazepam. Though this possibility cannot be excluded, it does not seem, however, to explain the observed effects completely. The fact that, for a given (fixed) footshock, the different doses of a drug produce different effects clearly suggests an action of the drug on learning that is independent of the possible action of the footshock. Furthermore, this objection cannot be proposed for the multiple-trial situation in which the footshock remains the same for the two drugs. On the other hand, it could also be possible that the two drugs have different analgesic properties that might contribute to the differences in learning. As far as $\beta-C C M$ is concerned, however, our group has previously shown that a dose of $1-\mathrm{mg} / \mathrm{kg} \beta$-CCM has no effect on pain threshold in mice (Prado de Carvalho et al., 1984). For $\beta-C C M$, we can thus rule out a possible explanation of this effect in terms of analgesia. But for diazepam, the question remains open. Finally, our present data confirm what we have previously suggested (Venault, Chapouthier, et al., 1986)-that is, that $\beta$-CCM has an action on acquisition rather than on retention (memory) itself.

Since, in the second experiment, the effects of $\beta$-CCM on learning were suppressed by administration of Ro 151788 , which is a specific antagonist of the benzodiazepine receptor, it could be assumed that these effects are mediated by this receptor. A similar conclusion was drawn from the results obtained in the one-trial passive avoidance 
task. Indeed, $\beta$-carbolines are known to bind with high affinity to the central benzodiazepine receptor (Braestrup et al., 1980; Guzman et al., 1984), and some have been proposed as endogenous ligands for these receptors (Braestrup et al., 1980; Pena, Medina, Novas, Paladini, \& De Robertis, 1986). Ro 15-1788 has been described as a specific, high-affinity benzodiazepine receptor ligand that reaches its sites of action within the central nervous system very rapidly, preventing and reversing dosedependently all effects that agonists and inverse agonists of the benzodiazepine receptor produce via this receptor (Haefely, 1988). It is, however, important to note that Ro 15-1788, classically used as a "neutral" antagonist of the benzodiazepine receptor, has effects of its own on learning behavior. Lal, Kumar, and Forster (1988) have shown an effect similar to that of $\beta-C C M$ in another negatively reinforced learning task; these authors hypothesized that pretreatment with Ro 15-1788 " may facilitate learning or memory processes by reversing a negative modulatory influence of endogenous diazepam-like ligands for benzodiazepine receptors."

A classical interpretation of our data could be that in spite of their similar intrinsic actions, $\beta$-CCM and Ro 151788 antagonize each other when administered simultaneously; however, this would not necessarily mean that the effects of $\beta$-CCM and Ro 15-1788 are mediated by the same sites on the benzodiazepine receptor. An alternative interpretation could be proposed. It could be assumed that Ro 15-1788 enhances (instead of antagonizes) the effects of $\beta$-CCM. Thus, combined administrations of $\beta$-CCM and Ro 15-1788 could produce the same effect as higher doses of $\beta$-CCM alone-that is, a weaker effect on performance. Experiments with several doses of $\beta$-CCM and several doses of Ro 15-1788 could help to clarify this point. However, when doses of both compounds are high, it is known that Ro 15-1788 has a clear (classical) antagonistic effect (see File \& Pellow, 1986, for review). Only synergy between very low doses of $\beta$ CCM and Ro 15-1788 could offer an answer to this point.

The question finally remains as to how $\beta$-CCM exerts its effects on learning. A first explanation of our data could be that $\beta$-CCM increases the level of arousal during the training session. This explanation would accord with the observation that, in rodents, arousal-enhancing drugs improve learning (Martinez, Jensen, \& McGaugh, 1983) and that several $\beta$-carbolines increase arousal (Ongini, Barzaghi, \& Marzanatti, 1983). The work by Jensen, Stephens, Sarter, and Petersen (1987) tends to confirm this view in rodents, by showing that cognitive effects of several BZ receptor ligands reflect changes in arousal or vigilance. Duka et al. (1987) found similar effects in man, where the $\beta$-carboline ZK 93246 improved performances in two cognitive tasks: a "logical reasoning task and a picture differences task which estimated concentration and attention, respectively" (p. 421). This interpretation is, however, difficult in the case of chicks, where it has been found that, on the contrary, $\beta$-CCM has a sedative effect (Venault, Prado de Carvalho, et al., 1986). An explana-
Table 3

Effects of $\beta$-CCM and Diazepam on Performance During a Passive Avoidance Test $30 \mathrm{sec}$ After Training

\begin{tabular}{|c|c|}
\hline Drug Injected & $\%$ Animals Avoiding \\
\hline \multicolumn{2}{|c|}{ Low-Shock Group } \\
\hline $\begin{array}{l}\text { Saline } \\
\beta \text {-CCM }(0.3 \mathrm{mg} / \mathbf{k g})\end{array}$ & $\begin{array}{l}10 \\
40^{*}\end{array}$ \\
\hline \multicolumn{2}{|c|}{ High-Shock Group } \\
\hline $\begin{array}{l}\text { Saline } \\
\text { Diazepam }(2 \mathrm{mg} / \mathrm{kg})\end{array}$ & $\begin{array}{l}87 \\
27 \dagger\end{array}$ \\
\hline
\end{tabular}

${ }^{*} \chi^{2}=4.80, p<.05 . \dagger \chi^{2}=11.00, p<.001$ between treated and controls.

tion for this observation could be that the action of $\beta$ carbolines in birds is markedly different from that seen in mammals.

We tried to confirm this arousal-enhancing interpretation with an experiment in which we used the passive avoidance situation, the only difference being that the test session was performed $30 \mathrm{sec}$ after the end of the training session instead of $24 \mathrm{~h}$ later. The high-shock groups consisted of 20 subjects, and the low-shock groups had 15 subjects. The data presented in Table 3 show that the results were the same as those obtained with a 24-h interval, suggesting an effect on learning.

The enhancing effects of $\beta$-CCM on learning could also be linked to its anxiogenic properties (and the amnesic effects of diazepam to its anxiolytic properties). However, in mice, where anxiogenic and convulsive effects of $\beta$ CCM as well as anxiolytic and anticonvulsive effects of diazepam have been extensively studied, the performanceenhancing effects of $\beta$-CCM were not seen in the dose range of the anxiogenic or convulsive effects of this drug. Indeed, the optimum dose for learning enhancement $(0.2$, $0.3 \mathrm{mg} / \mathrm{kg}$ ) is much lower than the anxiogenic dose in a conflict model $(1 \mathrm{mg} / \mathrm{kg})$ or the convulsive doses $(1-10 \mathrm{mg} / \mathrm{kg})$ in the same strain of mice. It might nevertheless be assumed that the doses used in the present work, insufficient to produce noticeable effects with such classical techniques as conflict models, are still sufficient to act on an emotional component of performance. Similar reflections could be made for the action of diazepam. These explanations do not contradict an effect on learning and memory processes. They simply imply that the improvement of performance by $\beta-C C M$ and the impairment of performance by diazepam in learning tasks on the one hand, and the effects in a conflict situation on the other, derive from common mechanisms involving anxiety.

\section{REFERENCES}

Braestrup, C., Nielsen, M., \& Olsen, C. E. (1980). Urinary and brain $\beta$-carboline-3-carboxylates as potent inhibitors of brain benzodiazepine receptors. National Academy of Sciences of the United States of America: Proceedings, 77, 2288-2292.

Braestrup, C., Schmiechen, R., Neef, G., Nielsen, M., \& PeterSEN, E. N. (1982). Interaction of convulsive ligands with benzodiazepine receptors. Science, 216, 1241-1243.

Chapouthier, G., Venault, P., Prado de Carvalho, L., Simi- 
AND, J., \& Rossier, J. (1984). Possible effects of $\beta$-carbolines on memory. Society for Neuroscience Abstracts, 10, 647.

Corda, M. G., Blaker, W. D., Mendelson, W. B., Guidotti, A., \& Costa, E. (1983). $\beta$-carbolines enhance shock-induced suppression of drinking in rats. National Academy of Sciences of the United States of America: Proceedings, 80, 2072-2076.

Dorow, R., Horowski, R., Paschelke, G., Amin, M. \& BraestruP, C. (1983). Severe anxiety induced by FG7142, a $\beta$-carboline ligand for benzodiazepine receptors. Lancet, 9, 98-99.

Duka, T., Stephens, W., Krause, W., \& Dorow, R. (1987). Human studies of the benzodiazepine receptor antagonist beta-carboline ZK 93 426: Preliminary observations on psychotropic activity. Psychopharmacology, 93, 421-427.

File, S. E., Lister, R. G., \&UTT, D. J. (1982). The anxiogenic action of benzodiazepine antagonist. Neuropharmacology, 21, 1033-1037.

FILE, S. E., PELLow, S. (1986). Intrinsic actions of the benzodiazepine antagonist Ro 15-1788. Psychopharmacology, 88, 1-11.

Guzman, F., Cain, M., Larsheid, P., Hagen, T., Cook, J. M., Schweri, M., SKolnick, P., \& PAUl, S. M. (1984). Biometric approach to potential benzodiazepine-receptor agonists and antagonists. Journal of Medicinal Chemistry, 27, 564-569.

HaEFELY, W. (1988). The preclinical pharmacology of flumazenil. European Journal of Anaesthesiology, 52, 25-36.

Hunkeler, W. H., Mohler, L., Pieri, L., Polc, P., Bonetti, E. P., Cumin, R., SchaffNer, R., Haefely, W. (1981). Selective antagonists of benzodiazepines. Nature, 290, 514-516.

Jensen, L. H., Stephens, D. N., Sarter, M., \& Petersen, E. N. (1987). Bidirectional effects of carbolines and benzodiazepines on cognitive processes. Brain Research Bulletin, 19, 359-364.

LAL, H., KumAR, B., \& Forster, M. J. (1988). Enhancement of learning and memory in mice by a benzodiazepine antagonist. FASEB Journal, 2, 2707-2711.

LISTER, R. G. (1985). The amnesic action of benzodiazepines in man. Neuroscience \& Biobehavioral Reviews, 9, 87-94.

Martinez, J. L., JR., Jensen, R. A., \& McGaugh, J. L. (1983). Facilitation of memory consolidation. In J. A. Deutsch (Ed.), The physiological basis of memory (2nd ed., pp. 49-70). New York: Academic Press.
Ninan, P. T., Insel, T. M., Cohen, R. M., Cook, J. M., Skolnick, P., PaUL, S. M. (1982). Benzodiazepine receptor-mediated experimental "anxiety" in primates. Science, 218, 1322-1334.

OAKLEY, N. R., Jones, B. J. (1982). Differential pharmacological effects of $\beta$-carboline-3-carboxylic acid esters. Neuropharmacology, 21, 587-589.

Ongini, E., Barzaghi, C., \& Marzanatti, M. (1983). Intrinsic and antagonistic effects of beta-carboline FG 7142 on behavioral and EEG actions of benzodiazepines and pentobarbital in cats. European Journal of Pharmacology, 95, 125-129.

Pena, C., Medina, J. H., Novas, M. L., Paladini, A. C., De ROBERTIS, E. (1986). Isolation and identification in bovine cerebral cortex of n-butyl $\beta$-carboline-3-carboxylate, a potent benzodiazepine binding inhibitor. National Academy of Sciences of the United States of America: Proceedings, 83, 4952-4956.

Polc, P., Bonetti, E. P., Schaffner, R., Haefely, W. (1982). A three-state model of the benzodiazepine receptor explains the interactions between the benzodiazepine antagonist Ro 15-1788, benzodiazepine tranquilizers, $\beta$-carbolines and phenobarbitone. NaunynSchmiedebergs Archives of Pharmacology, 321, 260-264.

Prado de Carvalho, L., Grecksch, G., Cavalheiro, E. A., Dodd, R. H., Chapouthier, G., \& Rossier, J. (1984). Characterization of convulsions induced by methyl $\beta$-carboline-3-carboxylate in mice. European Journal of Pharmacology, 103, 287-293.

Prado de Carvalho, L., Grecksch, G., Chapouthier, G., \& RossIER, J. (1983). Anxiogenic and non-anxiogenic benzodiazepine antagonists. Nature, 301, 64-66.

Venault, P., Chapouthier, G., Prado de Carvalho, L., Simiand, J., Morre, M., Dodd, R. H., \& Rossier, J. (1986). Benzodiazepine impairs and $\beta$-carboline enhances performance in learning and memory tasks. Nature, 321, 864-865.

Venault, P., Prado de Carvalho, L., Brown, C. L., Dodd, R. H., Rossier, J., \& Chapouthier, G.' (1986). The benzodiazepine receptor ligand methyl $\beta$-carboline-3-carboxylate is both sedative and proconvulsant in chicks. Life Sciences, 39, 1093-1100.

(Manuscript received April 23, 1990; revision accepted for publication September 18, 1990.) 